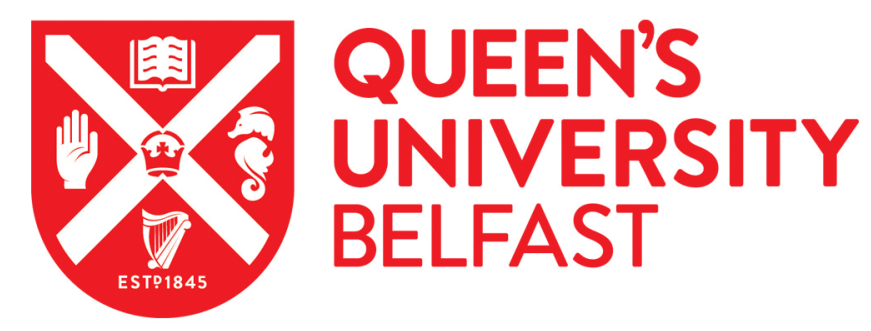

\title{
The challenges on the family unit faced by younger couples affected by prostate cancer: A qualitative study
}

Collaço, N., Wagland, R., Alexis, O., Gavin, A., Glaser, A., \& Watson, E. K. (2018). The challenges on the family unit faced by younger couples affected by prostate cancer: A qualitative study. Psycho-oncology.

https://doi.org/10.1002/pon.4944

Published in:

Psycho-oncology

Document Version:

Peer reviewed version

Queen's University Belfast - Research Portal:

Link to publication record in Queen's University Belfast Research Portal

Publisher rights

(c) 2018 John Wiley \& Sons, Ltd. This work is made available online in accordance with the publisher's policies. Please refer to any applicable terms of use of the publisher.

\section{General rights}

Copyright for the publications made accessible via the Queen's University Belfast Research Portal is retained by the author(s) and / or other copyright owners and it is a condition of accessing these publications that users recognise and abide by the legal requirements associated with these rights.

Take down policy

The Research Portal is Queen's institutional repository that provides access to Queen's research output. Every effort has been made to ensure that content in the Research Portal does not infringe any person's rights, or applicable UK laws. If you discover content in the Research Portal that you believe breaches copyright or violates any law, please contact openaccess@qub.ac.uk. 
The challenges on the family unit faced by younger couples affected by prostate cancer; a qualitative study.

Nicole Collaço ${ }^{1 *}$, Richard Wagland ${ }^{2}$, Obrey Alexis $^{1}$, Anna Gavin $^{3}$, Adam Glaser ${ }^{4}$, Eila K Watson ${ }^{1}$

${ }^{1}$ Faculty of Health and Life Sciences, Oxford Brookes University, Jack Straws Lane, Oxford, OX3 0FL

${ }^{2}$ Faculty of Health Sciences, University of Southampton, S017 1BJ

${ }^{3}$ Northern Ireland Cancer Registry School of Medicine, Dentistry and Biomedical Sciences, Centre for Public Health, Queen's University, Belfast, BT12 6BA

${ }^{4}$ Leeds Institute of Cancer and Pathology, Faculty of Medicine and Health, University of Leeds, Worsley Building, Leeds, LS2 9NL

Short Title: Family challenges for younger couples affected by prostate cancer

*Correspondence to:

Nicole Collaço ${ }^{1}$

PhD Student

Faculty of Health and Life Sciences

Oxford Brookes University

Jack Straws Lane

Marston

Oxford

OX3 0FL

Tel: 01869482785

Email: nicole.collaco-2016@brookes.ac.uk 


\begin{abstract}
Objective:

The number of younger men being diagnosed with Prostate cancer $(\mathrm{PCa})$, (aged $\leq 65)$ is increasing. It is recognised that $\mathrm{PCa}$ and treatment side effects can have a significant impact on quality of life. This study explores the challenges faced by younger couples affected by PCa with dependent children (under 18 years) or young adults (18-29 years) in their families.
\end{abstract}

\title{
Methods:
}

Twenty-three men with PCa and their partners were interviewed (separately) by telephone. Participants were recruited from respondents to the Life After Prostate Cancer Diagnosis (LAPCD) national survey. Men were three to five years post-diagnosis, and following a range of treatment pathways. Data were analysed using the Framework approach.

\section{Results:}

Younger couples affected by PCa felt challenged by issues relating to their parental role and the dynamics within the family. Five main themes emerged: difficult conversations about PCa diagnosis; parental perceptions of the impact of diagnosis on children; parental responses to the impact of $\mathrm{PCa}$ on the family; shielding, coping and normalising strategies; and levels of support.

\section{Conclusions:}

A diagnosis of PCa can cause significant disruption to the family unit and the quality of life of its members. Support programmes offering guidance to children/young adults affected by PCa in their family, and addressing the concerns of parents may help families to better adapt. Encouraging clinical professionals to initiate conversations with younger couples about their children may be a way forward in directing appropriate support. Further research is needed to elucidate appropriate, effective supportive interventions.

Keywords: Cancer, oncology, children, couples, dyad, family, prostate cancer, qualitative, LAPCD 


\section{Background}

Prostate cancer (PCa) is a common cancer in men in the UK, affecting over 47,000 men annually[1]. $\mathrm{PCa}$ is often considered an illness of older men, with $50 \%$ aged 70 and above. However, evidence indicates $24.2 \%$ of cancer cases occur in individuals aged between 21 and 55 years [2], i.e. during child rearing years. Also, the number of younger men being diagnosed with $\mathrm{PCa}$, aged $\leq 65$ has increased nearly six-fold over the past two decades[3], linked to increases in prostate-specific antigen (PSA) testing[4]. Therefore, a proportion of younger men affected by PCa (aged $\leq 65$ years) are likely to have young children (0-18 years) and/or young adults (YA) (19-29 years).

PCa and treatment side effects can cause incontinence, erectile dysfunction, fatigue, hot flushes and changes to men's mental wellbeing[5]. These symptoms may disrupt the established role of each member of the husband/partner-wife/partner dyad, by impacting upon men's ability to work, the family's financial situation and difficulties in maintaining intimate relationships[6]. These challenges may further disrupt the relationship dynamics within couples and their families[7], creating adjustment difficulties for children or young adults. Studies suggest a parental cancer diagnosis and treatment can result in extensive changes to the lives of the whole family[8]. Parents may feel challenged by the concerns, worries and questions of their children[9]. Feelings of guilt may be experienced by parents who feel unable to sufficiently fulfil parental roles as precedence is given to caring roles for their husband/partner[10].

Much of the research on parental cancer is focused on women with breast cancer and their partners[11]. A review of the literature on the experience of parents with cancer who care for young children (ages 3-7) found most studies were conducted in the US, and Scandinavian countries, with only one reported study undertaken in the UK[12]. Despite findings linking parental illness and changed dynamics on family functioning, little research has been conducted on fathers who have cancer[13], or more specifically on how PCa may affect family functioning in younger couples, and what challenges it creates. Thus, there may be service gaps in this area on how best to support younger families.

The World Health Organization defines young adulthood between the ages of 12-24 years[14], but more recent studies have defined 'young' adulthood extending up to the age of 29 years[15]. Children $<30$ years are more likely to be living at home, while those not living at home may nonetheless depend on parental support- physically, psychologically, socially, and economically[16]. Previous research on PCa has distinguished younger men with PCa using an age cut off of 65 years[6,17]. For the purpose of this study, 'younger families' is defined as a couple in which the man with PCa is aged 65 and under, and the couples have children under the age of 30 . This study therefore aims to explore the challenges on the family unit of younger couples affected by PCa, to 
better understand family dynamics when affected by PCa and inform how pathways of care can be developed to address their needs and that of their children.

\section{Methods}

\section{Recruitment and data collection}

This paper focuses on the findings from a study which is part of a large UK-wide mixed methods study: Life After Prostate Cancer Diagnosis (LAPCD)[18].

Eligible participants were identified through cancer registries in England, Wales and Northern Ireland, and through hospital activity data in Scotland, and invited by their treating centre to complete a postal questionnaire. Surveys were returned to Picker Institute Europe who managed the data. Following the survey, the survey provider sent the research team a random sample of contact details for respondents aged $\leq 65$, who had indicated they and their partner/spouse would be interested in participating in a telephone interview.

Maximum variation sampling was conducted according to treatment type, ethnicity and survey responses to ensure a wide range of experiences were explored. Selected participants were posted an invitation pack which included an invitation letter, participant information sheet, reply slip and prepaid envelope for both the survey respondent and his partner. Couples who returned their reply slips were contacted, and interviews were arranged to be conducted separately. Written and verbal consent was obtained from all participants. Couples in which only one partner wanted to take part in an interview were excluded. Children of younger couples were not interviewed as the original focus of the project was to explore the experiences and needs of younger couples affected by PCa. However, after analysis, the impact of PCa on family dynamics was identified to be an important part of their experiences and is therefore the focus of this paper.

\section{Interview procedures}

The interview topic guide was informed by a metasynthesis of literature we conducted on couples affected by $\mathrm{PCa}[19]$. Interviews comprised open-ended questions and prompts to encourage couples to talk about their PCa experiences, and its impact on their lives. Participants were asked if and how PCa impacted upon their family, which prompted couples to report on their perception of the impact on their children and their parental role. However, sometimes couples reported experiences of the impact of PCa on family life without prompting.

Men with PCa and their partner/wife were interviewed separately to allow each participant to describe their experiences without the presence of their partner potentially influencing their account. Telephone interviews were conducted by a female researcher (NC) between August 2016-July 2017 and were 30-60 minutes in duration. $\mathrm{NC}$ received training prior to commencing interviews and had 
conducted pilot interviews. Transcripts were not shared with participants for comments or correction in order to keep partners' versions confidential from each other.

\section{Data Analysis}

Interviews were transcribed verbatim and analysed using the Framework Method[20]. The first step involved familiarisation of transcripts through re-reading and reflection of the data. The Framework Method allowed for dyadic analysis and therefore data to be analysed at the level of the couple. Dyadic analysis drew upon the multi-perspective analysis methodology of Yosha et al,[21]. This method involved the creation of a table of patient and partner quotes which was adapted for the Framework analysis process by creating tables consisting of codes that were developed to create themes and subthemes relevant to the man with $\mathrm{PCa}$ and his partner. This was a pivotal stage in bringing together couples' experiences in a transparent and clear way. The adaptation of Yosha et al's [21] multiperspective approach was added to the Framework matrix which included a column of dyadic summaries that were created based on these codes, and therefore allowed greater depth of analysis at the level of the couple. Word and Xcel programmes were used to manage the data. Summaries also included field notes of the interviews conducted.

Codes were related to the topics discussed in the interviews, and formed the initial thematic framework based on these key topics; for example, healthcare experiences, relationships, and family. The extent of agreement with each theme were discussed between members of the research team (NC, $\mathrm{EW}, \mathrm{RW}, \mathrm{OA}$ ), and further revisions were made accordingly. This formed the working analytical framework which was then applied to the rest of the dataset (dyadic summaries) using existing categories and codes. The last stage involved interpreting the data through exploring potential overlaps and contrasts between the interviews of each partner; informed by Eisikovits and Koren[22]. Focus was given to the thematic framework regarding family functioning and children for this paper (see supplementary file 1). Data saturation was reached for all themes after 17 interviews.

The Consolidated Criteria for Reporting Qualitative Research (COREQ) guidelines[23] were followed in reporting the study findings (see supplementary file 2).

\section{Ethics}

NRES approval (North East-Newcastle \& North Tyneside 1. REC Reference no: 15/NE/0036) was granted for the wider LAPCD study, and this sub-study.

\section{Results}

\section{Study sample}


Forty-six couples were invited to take part, of which 28 couples agreed and were interviewed (response rate $=61 \%$ ). Four couples whose children were over the age of 29 , and one couple who had no children were interviewed as part of the work but excluded from this analysis. Data from 23 couples were included in this analysis. Men received a range of different treatments. Table 1 show full demographic characteristics.

\section{Themes}

Five themes were identified: 1) Difficult conversations about PCa, 2) parental perceptions of the impact of the diagnosis on children, 3) parental responses to the impact of PCa on the family, 4) shielding, coping and normalising strategies, and 5) levels of support.

\section{Difficult conversations about PCa}

One of the major challenges posed to younger couples was deciding if, when and how to initiate a conversation with their children about the diagnosis of PCa. In general, children (aged $<13$ years) were not told, as parents felt they were too young to understand. Parents also did not want the diagnosis to add stress to the challenges of school-age children. One couple chose to wait until their children's exams had finished before telling them, but found keeping it from them challenging: “[...]my son was doing his A levels and my daughter was doing her GCSE's, and I didn't know what sort of effect that would have so we waited until they finished their exams before we told them. We found we couldn't really talk at home, you know we might be overheard so we used to just say, oh we're going for a walk [...]" (dyad 8).

Some couples with children (aged $\geq 13$ years old) told them about the PCa diagnosis, although universally this was considered a difficult conversation. One couple described this process as: "sort of felt like throwing a grenade at the floor, and just hurting them all” (dyad 15). For many parents, although they informed their children of the diagnosis, they rarely discussed this with them further unless asked, wishing to avoid creating further anxiety.

A few couples had differing views within the dyad of whether/when to tell their children. For example, the husband of one couple wanted to delay this conversation, while his wife insisted the children should know immediately: "I think the only time we were probably at odds were telling people. I insisted that the kids were told immediately because [daughter] was living at home [...]. He didn't want to tell her and I think with hindsight I probably bulldozed him into telling [daughter], when perhaps he could have done with waiting a couple of days to get his head round it” (dyad 19). 


\section{Parental perceptions of the impact of diagnosis on children}

Couples varied in their perception of the impact PCa on their children. Some felt their children were coping well. This was influenced by men appearing to manage well with the impact of PCa and thus, maintaining normality. Some parents felt that keeping their children informed was helpful for them.

There were also parents who felt their children struggled to come to terms with the PCa diagnosis, which was more common in children whose father was significantly impacted physically and emotionally by the side effects of treatment. One couple (man had advanced cancer) perceived a big change in their family dynamics and felt they had to "walk on eggshells" around each other following their son's [in his early 20's] subsequent diagnosis of acute depression; possibly a consequence of him struggling to come to terms with their future as a family: "He was diagnosed with acute depression, he had to go on anti-depressants for a year, he couldn't work, every time he would look at his dad he would see death behind him... it was hell, it affected all of us, we were all walking around on each other for about 6 months" (dyad 5).

Couples sometimes described how their children differed in their reactions, and some appeared to cope better than others: "I think my son took it in a much more sort of 'well you're not going to die, you're going to be fine, you're going to have treatment and it's all going to be positive', he put a positive spin on it because he's a different personality compared to my daughter who was a bit more defensive and put a wall up if it was brought up" (dyad 12).

\section{Parental responses to the impact of PCa on the family}

How parents responded to the implications of PCa on their family life varied across couples and could change with time. Following reflection, one father altered his priorities with regards to his daughter: "I want to see my daughters grow, but I started enjoying more the moment rather than thinking I gotta see my daughter get married, you start thinking, well she's 2, I'm going to enjoy her now and that was key" (dyad 1).

For a few couples, the experience of PCa was deemed more stressful due to having younger children and dealing with a diagnosis of $\mathrm{PCa}$ at this point in their life as a younger family: "When he got diagnosed our children were young. I can remember thinking gosh this is really really stressful...it's all, you're gonna die type of scenario running through your mind and I think it probably was because we were younger as well” (dyad 2).

Treatment side effects played a role in the functioning of some families. In one couple, the husband described how hormone treatment affected his parental role and caused him to withdraw from his family: "I didn't know that it had given me so much harm at the time, in terms of how it affected my 
behaviour. I didn't want to be around anyone. I didn't realise that I had stepped back from the family, stepped back from the kids. The hormone changed me completely.” (dyad 15).

One of the side effects of PCa treatment and PCa itself is impotency. This caused stress for younger couples who wanted more children as they sought alternative approaches to fertility and influenced their treatment decisions. One younger couple perceived the PCa diagnosis imposed a time limit on when they could have more children which they found upsetting. Their response was to delay active treatment to give them more time to have a family: "I think probably the idea that we might not have children would be the biggest one and is probably more significant for us" (dyad 20).

\section{Shielding, coping and normalising strategies}

Various strategies were employed by parents to ease their children's adjustment to PCa and minimise its impact on them. For some couples, it was important to reassure children the treatment was helping to address the cancer. Maintaining normality by keeping busy and appearing not to be anxious about the diagnosis were also commonly employed by younger couples to support children and to minimise their concern: "I think because we have two small children, you just had to get on with it and kind of just keep going. I think that was our strategy for both of us. You can't lose it in front of your kids because then they know it's serious" (dyad 23).

For some couples, however, presenting a coping 'front' was challenging. The wife within one couple found it a struggle controlling her own emotions while also addressing those of her children together: "I felt very isolated, and our children were all coming to me with their grief and pain and because they're so young I don't really feel I can dump my feelings on them. [My son] at university doesn't want to see their Dad going through cancer, they don't want to see mum falling apart as well. So I did feel like I had to hold onto it all for everybody right the way through and it was very hard actually" (dyad 15).

Another concern for many younger couples was the potential hereditary nature of PCa. One couple hoped any worries their son might have about his own future risk of developing PCa would be alleviated by open discussion and by witnessing his dad's recovery following treatment: "I was able then to talk to my son, because I didn't want him to be scared of this, so he saw the surgery, he saw my recovery and I hope from that he can see that actually Dad's okay and it's nothing for him to be frightened of. So I think it's very positive in a way" (dyad 17).

Some couples perceived their children as trying to protect them by hiding their true feelings from them. In one family, the daughters reportedly sought emotional support from their older brother who had asked them not to reveal their concerns to their parents: "We handled it well and (son) says; 
'mum, you know I had the girls on the phone to me in tears, but I made them not tell you because I thought you had enough to worry about... we were all there for each other" (dyad 19).

\section{Levels of support}

\section{Support for parents}

Different levels of support were reportedly provided within the family and externally throughout the PCa experience. Young adult children were often a source of practical support for their parents: " $I$ think our children were quite helpful [...], when (husband) was in hospital they were just helpful in helping me just doing general jobs” (dyad 8).

\section{Support for children}

Children's ages could determine the types of external support available. Some parents of young children chose to inform their school of the PCa diagnosis. Support from schools involved teachers 'keeping an eye' on the child's behaviour and educational progress. Children who were at university were able to receive support from university student services and access emotional support in the form of counselling: "My youngest son went to counselling at the university, and the elder of my sons ended up really quite depressed and ended up with student support, getting lots of help" (dyad 15).

Lack of support for the children of these couples was also reported by a few parents who had older children. One participant reported that her daughter spoke to her GP regarding counselling, but found the experience unsupportive: "My daughter would have liked to talk to somebody and she was way out, there was no opportunity of support for her, she ended up talking to her own GP, she found they didn't really feel understand what she was feeling” (dyad 20).

"My son... he worries about me and the cancer. He didn't want to talk to me or anyone about it, but he said he wanted something to help, but he didn't know what, and I didn't really know” (dyad 7).

\section{Discussion}

To our knowledge, this is the first study to explore younger couples' experiences of PCa and its impact on family functioning. Younger couples affected by PCa faced particular challenges in relation to their parental role and family dynamics. This included how to tell children about the PCa diagnosis, how to manage the impact on their children, as well as how to deal with their own responses to the impact on their family life. Younger families sometimes struggled to maintain normality and balance the pressures posed by PCa on parental roles, and sometimes had difficulty accessing the right type of support. 
Family systems theory (FST) offers a useful framework for considering our findings and the implications for practice. The theory purports that to understand the family system, the family must be viewed as a whole, as the functioning of one family member influences that of all the others[24]. Couples and children in our study sometimes employed strategies and behaviours to normalise and neutralise the impact of $\mathrm{PCa}$ in ways that had dominated family life. Family priorities, daily routines and problem-solving styles could become over-focussed around the illness, while other family goals and needs were neglected. In our study, members of some families sought to adjust to the impact of PCa by seeking to protect each other, with parents seeking to maintain normality and to appear to manage well for the sake of the children, while struggling to control emotions, or by children hiding their true feelings for fear of adding to their parents' concerns. Protective buffering in families through concealment and control of their emotions towards each other was similarly identified in a qualitative study focused on the communication between male spouses of women with breast cancer and their children [25]. There is also similarity between our study findings and a previous research study on mothers affected by breast cancer, who also reported difficulties in striving to maintain normality in order to protect their children[26]. An important concept of FST is that the family system can 're-balance' their priorities and find a place for illness while at the same time keeping it in its place. For example, some couples and their children were able to reset their priorities in the family through their changed approach to spending time with their child, being able to talk to their child about hereditary implications and siblings that were able to support each other. Gaining a better understanding of the behaviours and strategies family members employ to seek emotional control over the diagnosis may be helpful for them to move toward growth as a family.

Younger couples affected by PCa reported concerns and uncertainty about fertility, with some delaying active treatment due to their desire to have more children. Concerns have also been noted in qualitative research on men with testicular cancer where the threat to fertility was found to contribute to emotional distress[27]. Recognising that heritable forms of PCa are more common in younger men [28], couples in our study also worried about the potential hereditary implications for their sons.

Research has highlighted that mothers with breast cancer and children growing up in hereditary breast cancer families may experience diminished psychological wellbeing[29]. Greater information, and psycho-emotional support in this area may be critical in order to address the concerns of younger couples and their children.

For younger couples affected by an advanced diagnosis of $\mathrm{PCa}$, conversations about $\mathrm{PCa}$ were particularly challenging and there appeared to be a heightened level of distress and impact on family dynamics. Although relatively few studies have explored the impact of a diagnosis of advanced cancer on family dynamics, psychological distress in families affected by newly diagnosed advanced breast cancer has been reported[30]. Avoidance may be a common coping strategy amongst these families, 
however open communication has previously been recognised as an important factor in helping children cope with a parent's illness[31], and is an important interaction pattern identified in FST to aid family adjustment. In our study, couples thought carefully about how to tell their children about $\mathrm{PCa}$, and how to help them deal with the PCa diagnosis and its implications. Being open and honest was one way of doing this, although the degree of openness in family discussions was reportedly dependent on the ages of the children. FST proposes that the permeability of family boundaries (the extent and type of contact between family members) is influenced by the developmental age and needs of family members, and is therefore an important consideration when health professionals seek to address the support needs in the family [32]. A recent systematic review of psychosocial interventions designed to support children/adolescents (0-18 years) [33] suggested that young children may benefit from receiving information about their ill parent's physical experiences and changes that will have a direct impact on them. Whereas, adolescents may be more likely to benefit from information on how they can be involved with supporting parents, and how it may affect them personally[34]. Facilitating parents' awareness of, and access to, age-appropriate information resources on how to talk to children about cancer, and information for children may be a helpful step forward in managing communication challenges (e.g. CanTeen, Macmillan).

\section{Study Limitations}

A limitation of this study is that the couples' children were not interviewed and therefore the reported data of the impact of PCa on their children was assessed from the perspective of the couples only. The sample of younger couples interviewed in this study were three to five years post-diagnosis of PCa, so recall bias is possible. Also, the age ranges of the couples (30-66 years) and their children is broad (029 years), including children that were preschool, school-age, adolescent and young adult. Finally, the sample was not ethnically diverse, and ethnic differences in family functioning dynamics of couples affected by PCa remains an area to be explored in future research.

\section{Clinical Implications}

Having someone within the healthcare team or informal support services to help families address the emotional challenges they are facing may be helpful. The development of guidance programmes/workshops should be considered that support couples and their children to self-manage the impact of PCa as a family, in ways that allow engagement in non-illness family activities and priorities. It is important that information and advice are available to address the specific needs and concerns of younger families affected by PCa. This should include information on fertility (e.g. sperm banking, IVF) and potential hereditary implications for men's sons. Although online materials exist on how to manage some of the challenges of parenting whilst dealing with cancer, it is important that there are other forms of engaging, personal support available. 


\section{Conclusions}

PCa poses many challenges to younger couples and affects family dynamics and interactions between parents and their children. The challenges are similar to those of other younger couples with cancer, however as $\mathrm{PCa}$ is most often a cancer of older men, the particular concerns and needs of younger families affected by PCa may not always be considered by health professionals while focusing on the cancer itself. It is important that parents and their children have access to a service or resources which focus on the family as a unit to provide advice and support if required. Encouraging clinical professionals to ask the question, 'do you have kids?' may be one step forward in identifying parents with particular concerns, who can then be signposted to additional support services if required.

\section{Acknowledgements:}

This work is funded by Oxford Brookes University; sub-study to the Life After Prostate Cancer Diagnosis (LAPCD) study. The LAPCD study was funded by the Movember Foundation, in partnership with Prostate Cancer UK, as part of the Prostate Cancer Outcomes programme, grant number BO26/MO. We would also like to thank the participants who took part in this study.

\section{Conflicts of interests}

The authors declare no conflict of interest. 


\section{References}

1 Prostate Cancer UK. About Prostate Cancer http://doi.wiley.com/10.1111/bju.12745 (accessed Oct 15, 2017); DOI:10.1111/bju.12745.

2 NCI. National Cancer Institute: National Health Interview Survey https://www.researchgate.net/publication/10763686 (accessed May 31, 2018);

DOI:10.1200/JCO.2003.01.193.

3 Salinas CA, Tsodikov A, Ishak-Howard M, Cooney KA. Prostate Cancer in Young Men: An Important Clinical Entity. Nature Reviews Urology, 2014, 11, 317-323;

DOI:10.1038/nrurol.2014.91.

4 Young GJ, Harrison S, Turner EL, Walsh EI, Oliver SE, Ben-Shlomo Y, Evans S, Lane JA, Neal DE, Hamdy FC, Donovan JL, Martin RM, Metcalfe C. Prostate-Specific Antigen (PSA) Testing of Men in UK General Practice: A 10-Year Longitudinal Cohort Study. BMJ Open 2017; 7: e017729; DOI:10.1136/bmjopen-2017-017729.

5 Chambers SK, Occhipinti S, Schover L, Nielsen L, Zajdlewicz L, Clutton S, Halford K, Gardiner RA, Dunn J. A Randomised Controlled Trial of a Couples-Based Sexuality Intervention for Men with Localised Prostate Cancer and Their Female Partners.

Psychooncology. 2015; 24: 748-756; DOI:10.1002/pon.3726.

6 Harden, Northouse L, Mood D. Qualitative Analysis of Couples' Experience with Prostate Cancer by Age Cohort. Cancer Nurs. 2006; 29: 367-377; DOI:10.1097/00002820-20060900000004.

7 Corney R, Puthussery S, Swinglehurst J. Couple Relationships in Families with Dependent Children after a Diagnosis of Maternal Breast Cancer in the United Kingdom: Perspectives from Mothers and Fathers. J. Psychosoc. Oncol. 2016; 34: 413-431;

DOI:10.1080/07347332.2016.1199080.

8 Vannatta K, Ramsey RR, Noll RB, Gerhardt CA. Associations of Child Adjustment with Parent and Family Functioning: Comparison of Families of Women with and without Breast Cancer. J. Dev. Behav. Pediatr. 2010; 31: 9-16; DOI:10.1097/DBP.0b013e3181c82a44.

9 Kennedy VL, Lloyd-Williams M. Information and Communication When a Parent Has Advanced Cancer. J. Affect. Disord. 2009; 114: 149-155; DOI:10.1016/j.jad.2008.06.022.

10 Thastum M, Munch-Hansen A, Wiell A, Romer G. Evaluation of a Focused Short-Term Preventive Counselling Project for Families with a Parent with Cancer. Clin. Child Psychol. Psychiatry 2006; 11: 529-542; DOI:10.1177/1359104506067875. 
11 Götze H, Friedrich M, Brähler E, Romer G, Mehnert A, Ernst J. Psychological Distress of Cancer Patients with Children under 18 Years and Their Partners - a Longitudinal Study of Family Relationships Using Dyadic Data Analysis. Support. Care Cancer 2017; 25: 255-264; DOI:10.1007/s00520-016-3411-z.

12 Semple CJ, McCance T. Parents' Experience of Cancer Who Have Young Children: A Literature Review. Cancer Nursing, 2010, 33, 110-118;

DOI:10.1097/NCC.0b013e3181c024bb.

13 O’Neill C, McCaughan E, Semple C, Ryan A. Fatherhood and Cancer: A Commentary on the Literature. Eur. J. Cancer Care (Engl). 2013; 22: 161-168; DOI:10.1111/ecc.12021.

14 World Health Organisation. Adolescence: a period needing special attention - recognizingadolescence http://apps.who.int/adolescent/second-decade/section2/page1/recognizingadolescence.html (accessed Mar 4, 2018).

15 Arnett JJ, Žukauskienė R, Sugimura K. The New Life Stage of Emerging Adulthood at Ages 18-29 Years: Implications for Mental Health. The Lancet Psychiatry 2014; 1: 569-576; DOI:10.1016/S2215-0366(14)00080-7.

16 Stone J, Berrington A, Falkingham J. The Changing Determinants of UK Young Adults' Living Arrangements. Demogr. Res. 2011; 25: 629-666; DOI:10.4054/DemRes.2011.25.20.

17 Herold D, Hanlon, Movsas, Hanks. Age Related Prostate Cancer Metastasies. Urology 1998.

18 Downing A, Wright P, Wagland R, Watson E, Kearney T, Mottram R, Allen M, Cairnduff V, McSorley O, Butcher H, Hounsome L, Donnelly C, Selby P, Kind P, Cross W, Catto JWHH, Huws D, Brewster DH, McNair E, Matheson L, Rivas C, Nayoan J, Horton M, Corner J, Verne J, Gavin A, Glaser AW. Life after Prostate Cancer Diagnosis: Protocol for a UK-Wide Patient-Reported Outcomes Study. BMJ Open 2016; 6: e013555; DOI:10.1136/bmjopen-2016013555 .

19 Collaco N, Rivas C, Matheson L, Nayoan N, Wagland R, Alexis O, Gavin A, Glaser A. Prostate Cancer and the Impact on Couples: A Qualitative Metasynthesis. Support. Care Cancer 2018; 26: 21-22; DOI:10.1007/s00520-018-4134-0.

20 Ritchie J, Lewis J, Ritchie, J. \& Lewis J. Qualitative Research Practice - A Guide for Social Science Students and Researchers. Sage London, 2003; DOI:10.4135/9781452230108.

21 Yosha AM, Carroll JK, Hendren S, Salamone CM, Sanders M, Fiscella K, Epstein RM. Patient Navigation from the Paired Perspectives of Cancer Patients and Navigators: A Qualitative Analysis. Patient Educ. Couns. 2011; 82: 396-401; DOI:10.1016/j.pec.2010.12.019. 
22 Eisikovits Z, Koren C, Eisikovits ${ }^{1}$ Z. Approaches to and Outcomes of Dyadic Interview Analysis. Qual. Heal. Res. Qual Heal. Res Qual. Heal. Res. 2010; 20: 1642-1655;

DOI:10.1177/1049732310376520.

23 Tong A, Sainsbury P, Craig J. Consolidated Criteria for Reporting Qualitative Research (COREQ): A 32-Item Checklist for Interviews and Focus Groups. Int. J. Qual. Heal. Care 2007; 19: 349-357; DOI:10.1093/intqhc/mzm042.

24 Steinglass P. Family Systems Theory and Therapy: A Clinical Application of General Systems Theory. Psychiatr. Ann. 1984; 14: 582=586.

25 Forrest G, Plumb C, Ziebland S, Stein A. Breast Cancer in Young Families: A Qualitative Interview Study of Fathers and Their Role and Communication with Their Children Following the Diagnosis of Maternal Breast Cancer. Psychooncology. 2009; 18: 96-103; DOI:10.1002/pon.1387.

26 Billhult A, Segesten K. Strength of Motherhood: Nonrecurrent Breast Cancer as Experienced by Mothers with Dependent Children. Scand. J. Caring Sci. 2003; 17: 122-128; DOI:10.1046/j.1471-6712.2003.00219.x.

27 Matheson L, Boulton M, Lavender V, Protheroe A, Brand S, Wanat M, Watson E. Dismantling the Present and Future Threats of Testicular Cancer: A Grounded Theory of Positive and Negative Adjustment Trajectories. J. Cancer Surviv. 2016; 10: 194-205; DOI:10.1007/s11764-015-0466-7.

28 Levy-Lahad E, Friedman E. Cancer Risks among BRCA1 and BRCA2 Mutation Carriers. nature.com 2007; 96: 11-15.

29 Tercyak KP, Peshkin BN, Streisand R, Lerman C. Psychological Issues among Children of Hereditary Breast Cancer Gene (BRCA1/2) Testing Participants. Psychooncology. 2001; 10: 336-346; DOI:10.1002/pon.531.

30 Turner J, Kelly B, Swanson C, Allison R, Wetzig N. Psychosocial Impact of Newly Diagnosed Advanced Breast Cancer. Psychooncology. 2005; 14: 396-407; DOI:10.1002/pon.856.

31 Northouse LL, Cracchiolo-Caraway A, Appel CP. Psychologic Consequences of Breast Cancer on Partner and Family. Semin. Oncol. Nurs. 1991; 7: 216-223; DOI:10.1016/07492081(91)90035-N.

32 Mehta A, Cohen SR, Chan LS. Palliative Care: A Need for a Family Systems Approach. Palliat. Support. Care 2009; 7: 235-243; DOI:10.1017/S1478951509000303.

33 Ellis SJ, Wakefield CE, Antill G, Burns M, Patterson P. Supporting Children Facing a Parent's 
Cancer Diagnosis: A Systematic Review of Children's Psychosocial Needs and Existing Interventions. Eur. J. Cancer Care (Engl). 2017; 26: e12432; DOI:10.1111/ecc.12432.

34 Chowns G. "Until It Ends, You Never Know...": Attending to the Voice of Adolescents Who Are Facing the Likely Death of a Parent. Bereave. Care 2013; 32: 23-30;

DOI:10.1080/02682621.2013.779822.

35 Inhestern L, Haller AC, Wlodarczyk O, Bergelt C. Psychosocial Interventions for Families with Parental Cancer and Barriers and Facilitators to Implementation and Use - A Systematic Review. PLoS ONE, 2016, 11, e0156967; DOI:10.1371/journal.pone.0156967.

36 Bugge KE, Helseth S, Darbyshire P. Parents' Experiences of a Family Support Program When a Parent Has Incurable Cancer. J. Clin. Nurs. 2009; 18: 3480-3488; DOI:10.1111/j.13652702.2009.02871.x.

37 Davey MP, Kissil K, Lynch L, Harmon LR, Hodgson N. A Culturally Adapted Family Intervention for African American Families Coping with Parental Cancer: Outcomes of a Pilot Study. Psychooncology. 2013; 22: 1572-1580; DOI:10.1002/pon.3172.

38 Semple CJ, Mccaughan E. Family Life When a Parent Is Diagnosed with Cancer: Impact of a Psychosocial Intervention for Young Children. Eur. J. Cancer Care (Engl). 2013; 22: 219231; DOI:10.1111/ecc.12018.

39 Hasson-Ohayon I, Braun M. Being a Parent and Coping with Cancer: Intervention Development. Palliat. Support. Care 2011; 9: 149-152; DOI:10.1017/S1478951511000174. 